\title{
Moderating Effect of Age on the Link of Emotional Intelligence and Mental Health among High School Students
}

\author{
Jafar Shabani (Corresponding author) \\ Faculty of Educational Studies, Universiti Putra Malaysia \\ 43400 UPM Serdang, Selangor, Malaysia \\ Tel: 60-17-360-1749Ｅ-mail: jshabani@yahoo.com
}

Siti Aishah Hassan
Faculty of Educational Studies, Universiti Putra Malaysia
43400 UPM Serdang, Selangor, Malaysia
Tel: 60-13-351-9364 $\quad$ E-mail: siti_aishahh@putra.upm.edu.my

Aminah Ahmad

Faculty of Educational Studies, Universiti Putra Malaysia

43400 UPM Serdang, Selangor, Malaysia

Tel: 60-12-368-3411 E-mail: aminah@ace.upm.edu.my

Maznah Baba

Faculty of Educational Studies, Universiti Putra Malaysia

43400 UPM Serdang, Selangor, Malaysi

Tel: 60-17-360-1749Ｅ-mail: mazb@putra.upm.edu.my

Received: September 12, $2010 \quad$ Accepted: February 12, 2011 doi:10.5539/ies.v4n2p82

The research is financed by Malaysia CIMB Bank. No. 1215180111002 (Sponsoring information).

\begin{abstract}
This study examined whether, Emotional Intelligence (EI) can be considered as predictor for mental health and explored also the moderating effect of age on the link between EI with mental health among high school students. The participants in the study included $10^{\text {th }}, 11^{\text {th }}$, and $12^{\text {th }}$ grade students from 8 public high schools in Gorgan City, north of Iran. They were 247 high school students, specifically comprised of 124 boys and 123 girls, age ranged between 15 to 17 years old (83, Fifteen; 82, Sixteen; 82, Seventeen). The research design was an ex post facto and tested of alternative hypotheses. Two valid and reliable instruments were used to measure EI and mental health. Data analysis included frequencies, percentages, mean scores, simple regressions and moderated regressions. The result demonstrated that mental health can be influences by EI. In addition, age is not significant moderator for the relationships between EI with mental health.
\end{abstract}

Keywords: Education, Psychology, Emotional intelligence, Mental health, High school students

\section{Introduction}

Mental health is perceived as a positive source contributing to asset development individually, socially, and economically (WHO, 2004). The World Health Organization conceptualized mental health separate from mental ill-health and defined the concept as: a state of well-being in which the individual realizes his or her own abilities, can cope with the normal stresses of life, can work productively and fruitfully, and is able to make a contribution to his or her own community. (WHO, 2007, p. 1). Positive mental health is also link to better physical health, increased pro-social behaviors, and participation in less adverse behaviors in adolescence (Resnick, 2000). Better mental health outcomes in adolescents are characterized by greater adaptation in family, society, and school environment, improved quality of life (Hoagwood et al., 1996; USDHHS, 1999). Conversely, poor mental health and well-being 
(i.e. depression, low self-esteem) during the adolescent years can lead to adolescent health risk behaviors, school failure, physical ill-health, suicide, involvement in juvenile and criminal justice systems, negative life choices, and mental disorders in adulthood (Lewinsohn et al., 1993; Canals, et al., 2002; Trzesniewski et al., 2006; Hjemdal et al., 2007).

EI was originally recognized as having its roots in the concept of social intelligence (Thorndike, 1920; Salovey \& Mayer, 1990; Goleman, 1995). Later, researches provided evidence that the two concepts actually represent interrelated components of the same construct (Salovey \& Mayer, 1990; Bar-On et al., 2003; Lane \& McRae, 2004). Consequently, this broad construct was accurately referred to as "emotional-social intelligence" (Bar-On, 2006). Based on historical reference, traits such as the capacity to navigate through and to adapt to one's own environment and the possession of social and emotional "skills" are important not only to basic survival, but have implications in the areas of relationships, work, school, and emotional and mental health (Goleman, 1995; Salovey \& Mayer, 1990).

Conceptual models appearing most frequently in the literature include the Salovey-Mayer model (Mayer \& Salovey, 1997), the Goleman model (1998b), and the Bar-On model (2000). The above models and researchers revealed the implications of EI on mental and emotional health, relationships, self-motivation, adaptability, and problem solving, suggesting that without these skills or abilities, individuals will not be as successful. Elias et al., (2002), Bar-On (2006) and others have also claimed that the skills of Social Emotional Learning Model (SEL) and emotional-social intelligence can be taught and are generalizable across situations (i.e., work, school, social, etc.). It has been suggested that introduction of these skills may positively impact on school climate, by infusing interventions into multiple subject areas and encouraging prosocial behaviour, thus creating a more positive climate (Graczyk et al., 2000).

The popularity of the concept of EI for the past decades has led researchers to examine its potency in various areas of human functioning. Among the areas with the strongest connections to EI is developmental, educational, clinical and counselling, industrial and organizational psychology. Hence, characteristic or ability EI were related to physical and mental health (Ioannis \& Ioannis, 2005), life satisfaction and well-being (Martinez-Pons, 1997; Palmer et al., 2002), life success (Bar-On, 2001; Goleman, 1995), vocational stress (Bar-On et al., 2000; Nikolaou \& Tsaousis, 2002; Slaski \& Cartwright, 2002), job success and performance (Dulewicz \& Higgs, 1998; Vakola et al., 2004), individual performance (Lam \& Kirby, 2002), interpersonal relationships (Fitness, 2001; Flury \& Ickes, 2001), academic achievement (Van der Zee et al., 2002; Parker et al., 2004) leadership (Palmer et al., 2000), etc.

Taylor (2001) argued that if you are emotionally intelligent then you can cope better with life's challenges and control your emotions more effectively, both of which contribute to good mental and physical health. They stated that EI was strongly correlated with both, physical and psychological health. Furthermore, Salovey (2001) suggested that emotions' manifestation has a positive impact on physical health when people are confident about their abilities to regulate them. He proposed that the best way of dealing with the expression of our feelings in terms of our health is through the rule of "golden mean". "We may need to express negative feelings, but in a way that is neither mean spirited nor stifled" (p. 170). Moreover, Dulewicz, et al., (2003), examined the role emotional self-management such as stress, distress, morale and poor quality of working life play in everyday life.

The findings of some research indicated that numerous significant differences among the age groups that were compared were relatively small (Bar-On, 1997). The older groups on the EI scale scored higher, while the respondents in their late forties and early fifties received the highest mean score. Based on a research observation carried out by Bar-On and Parker (2000), there was a similar increase in EI with age in children and adults. As Goleman (1998) pointed out, the influence of age proposes that EI goes up with age, at least up to the fifth decade in life (Bar-On, 2000). Goleman (1998) stated that there is a relationship between age and EI. Golman pointed out that EI increases with age.

There is some evidence that EI development and emotional experiences are helpful for health. Also, there is a significant relationship between awareness of emotional experiences and health. On the whole, it seems emotional functions including EI and its components can be used as an instrument in relates with individual mental health. Researcher suggests a significant relationship between EI and mental health (Goleman, 1995; Salovey \& Mayer, 1990; Ioannis \& Ioannis, 2005). Therefore, the aim of this study was to investigate the link of SI and EI with mental health. Also, this study was to examine the role of age as moderating effect on the relationship between EI and mental health.

\section{Method}

\subsection{Participants}

Participants in the study included boy and girl high school students. The sample was made up of Two hundred and forty seven Iranian high school students in Gorgan city, north of Iran (124 male 123 female) were recruited as 
respondents in this study during 2009/2010 academic year. Their ages ranged from $15-17$ years $(83$, Fifteen $=$ $33.20 \%, 82$, Sixteen $=33.60 \%, 82$, Seventeen $=33.20 \%$ ).

\subsection{Measures}

Two instruments were used to collect data from the Respondents. They include:

\subsubsection{General Health Questionnaire (GHQ 28, Goldberg, 1972; Goldberg \& Williams, 1998);}

In 1972, Goldberg developed a simple questionnaire, the General Health Questionnaire (GHQ), which is the most widely used instrument for detecting non-psychotic psychiatric "Cases". The GHQ is a self-administered screening questionnaire used to diagnose psychiatric disorders both in primary care and in the community. The main benefits of GHQ are that it is easy to administer, brief, and objective. Several versions of GHQ are available: there is a 60-item version, and shorter versions (comprising 30, 28 and 12 items). The 28-item version (GHQ-28) developed by Goldberg and Hillier (1979) is constructed on a different basis when compared with the other versions. Responses are responded on a four-point scale ranging from "less than usual", to "much more than usual". Of the four possible ways of scoring this instrument (Goldberg \& Williams, 1998), for this study the simple Likert method $(0-1-2-3)$ was chosen. The measure yields an overall health scores (range 0-84) and is composed of four subscales described as somatic symptoms, anxiety and insomnia, social dysfunction and depression. High scores indicate high levels of psychological strain. The measure was found to have an acceptable level of internal consistency reliability $($ alpha $=0.92)$. High score on this scale indicate poor general health.

\subsubsection{Emotional Intelligence Inventory, Youth Version (EQ-i YV, Bar-On \& Parker, 2000b);}

Utilized to measure EI, the Bar-On Emotional Quotient Inventory: Youth Version (EQ-i: YV) was developed by Reuven Bar-On, Ph.D. and James D.A. Parker, Ph.D., and published by Multi-Health Systems, Inc., in 2000. The EQ-i: YV was developed to measure emotional intelligence in adolescent populations, based on the theoretical basis of the Bar-On model of social and emotional intelligence. This 60 -item inventory is a self-report instrument designed to measure emotional intelligence in young people aged 7 to 18 years. The instrument measures a cross-section of abilities and competencies that constitute the core features of emotional intelligence. Responses are invited on a four-point scale ranging from "very seldom true of me" to "very often true of me". For this study the simple Likert method (1-2-3-4) was chosen. The measure yields an overall EI scores (range 0-240). The scale has a Cronbach alpha of 0.74 .

\section{Results}

To carry out the main objective of the current study, the obtained data were subjected to a number of statistical analyses by using statistical package for social sciences (SPSS 17.0). Although the analysis most pertinent to the objectives of the study was Descriptive statistics, moderated and simple Regression Analyses was also used.

\subsection{Descriptive Statistics}

Table 1 presents the mean and standard deviations of all the observed variables. Descriptive statistics is worked out to know the pattern of score distribution. A perusal of Table 1 reveals that the mean score on EI is 2.90 with the SD of .29; on total mental health the mean score was .91 with the SD of .43. (See Table 1)

\subsection{Simple Regression Analysis (SRA)}

SRA was computed to assess the strength of relationship between dependent variable and independent variables. SRA provides an opportunity with little ambiguity to assess the importance of the predictor to the overall relationship. The results of regression analysis for the dependent variable (total mental health) are presented in Table 2. It is clear from the results that the regression analysis accepted EI as a significant predictor of total mental health. This table shows that $\mathrm{R}=.598, \mathrm{R}^{2}=.357$, adjusted $\mathrm{R}^{2}=.354$ and $\{\mathrm{F}(2,245)=136.099, \mathrm{P}<.05\}$. This $\mathrm{R}^{2}$ means that $35.7 \%$ of the variance in mental health increase is explained by EI. Based on the values reported in the variable, the beta coefficient for EI was -.880. This means that EI makes the strongest contribution to explaining the dependent variable (total mental health). It suggest that one standard deviation increase in EI is followed by -.880 standard deviation increase in mental health (See table 2).

\subsection{Moderated Regression (MR)}

MR was employed in examining the effects of moderator variable (gender) on the relationships between the independent variable (EI) and the dependent variable (MH).

MR involves two steps. First, it is needed to form two regression equations, one includes the first-order only and second model include the first-order effects as well as a product term including the moderator variable. In this research, the product term is age. The following are the two equations formed that derived from the regression procedure by entering independent variables and product term block by block in order to create two models. 
Table 3 shows that parameters of model 1 were $\mathrm{R}=.598, \mathrm{R}^{2}=.357$, adjusted $\mathrm{R}^{2}=.354, \mathrm{~F}(2,245)=136.099$, and 'Sig Value' $=.000$ with a $\mathrm{p}<.05$. This $\mathrm{R}^{2}$ indicates that $35.7 \%$ of the variance in mental health increase is explained by emotional intelligence. Model 1 does not include the product term and, thus, ignores a possible moderating effect of age. To find out whether the potential moderating effect of age on the EI with mental health relationship, we need to interpret the model 2 in Table 3.

Model 2 in Table 3 shows results after the product term has entered the equation. As shown in Table 3, the addition of the product term resulted in an $\mathrm{R}^{2}$ change of $.000, \mathrm{~F}$ change $(1,244)=.003$, Sig. F change $=.955$ at the $\mathrm{p}<.05$. This result do not supported the presence of a moderating effect. In other words, the moderating effect of age cannot explain of variance in mental health. The result suggests that the age is not important moderated factors on relationship between EI and mental health.

\section{Discussion}

The results in this study found SI was significantly and negatively correlated with mental health score. EI was found to be the strongest predictor for mental health scores. So, the findings of this study supported a positive effect of EI on students' mental health scores. The overall regression model was successful in explaining approximately $35.7 \%$ of the proportion variance explained in mental health scores. This finding is in line with (Bar-On, 2001; Goleman, 1995; Martinez-Pons, 1997; Palmer et al, 2002; Ioannis \& Ioannis, 2005). The findings of provide evidence that age does not moderating effect on the relationship between independent variable (EI) and dependent variable (MH). This finding is disagrees with (Bar-On, 1997, 2000; Golman 1998).

\section{Conclusion}

The main purpose of the present study conducted to explain the role of EI on mental health (somatic symptom, anxiety, social dysfunction and depression) among high school students. The present investigation also was to test the moderating effects of age on the relationship of EI with mental health. This research found that student's mental health can be predicted by EI. The R-squared of .357 implies that the predictor variable (EI) explain about $35.7 \%$ of the variance in the mental health (dependent variable). The findings also proved that age didn't pose any moderate effect on the relationships between the EI and mental health scales and sub- scales. The moderating effect of age explains $.0 \%$ of variance in mental health above and beyond the variance explained by EI. These findings suggest that EI is important and should be encouraged in school and students mental health life. Therefore, this information will be important to community counsellors, teachers, school counsellors, and parents, all of whom are concerned with both the academic and social-spiritual development of children, and with the climate of children's learning environments.

\section{Acknowledgment}

We thank the administration officers at all schools of this research sample for giving us information about students in their schools. We also appreciate the contribution of high schools students by participating in this research, thus allowing us to collect the necessary data for the study.

\section{References}

Bar-On, R. (1997). The Emotional Intelligence Inventory (EQ-I): Technical Manual. Toronto, Canada: Multi-Health Systems.

Bar-On, R. (2000). Emotional and social intelligence: Insights from the Emotional Quotient Inventory. The handbook of emotional intelligence, 363-388

Bar-On, R. (2001). Emotional intelligence and self-actualization. In J. Ciarrochi, J.P. Forgas, \& J.D. Mayer (Eds), Emotional intelligence in every day life: A scientific inquiry (pp. 82-97). Philadelphia, PA: Psychology Press.

Bar-On, R. (2006). The Bar-On model of emotional-social intelligence (ESI). Psicothema, 18, 13-25

Bar-On, R., Brown, J. M., Kirkcaldy, B. D., \& Thome, E. P. (2000). Emotional expression and implications for occupational stress; an application of the Emotional Quotient Inventory (EQ-i). Personality and Individual Differences, 28 1107-1118

Bar-On, R., \& Parker, J. D. A. (2000). The handbook of emotional intelligence: Theory, development, assessment, and application at home, school, and in the workplace. San Francisco, CA: Jossey-Bass

Bar-On, R., \& Parker, J. D. A. (2000b). Bar-On Emotional Quotient Inventory: Youth Version. Technical Manual. North Tonawanda, NY: Multi-Health Systems. Inc.

Bar-On, R., Tranel, D., Denburg, N., \& Bechara, A. (2003). Exploring the neurological substrate of emotional and social intelligence. Brain, 126(8), 1790. 
Canals, J., Domènech-Llaberia, E., Fernández-Ballart, J., \& Martí-Henneberg, C. (2002). Predictors of depression at eighteen. European Child \& Adolescent Psychiatry, 11(5), 226-233

Dulewicz, v., \& Higgs, M. (1998). Emotional intelligence: Can it be measured reliably and validly using competency data. Competency, 6, 1-15

Dulewicz, v., Higgs, M., \& Slaski, M. (2003). Measuring emotional intelligence: content, construct, and criterionrelated validity. Journal of Managerial Psychology, 18, 405-420

Fitness, J. (2001). Emotional intelligence and intimate relationships. In J. Ciarrochi, J.P. Forgas, \& J.D. Mayer (Eds), Emotional intelligence in every day life: A scientific inquiry (pp. 98-112). Philadelphia, PA: Psychology Press.

Flury, J., \& Ickes, W. (2001). Emotional intelligence and empathetic accuracy. In J. Ciarrochi, J.P. Forgas, \& J.D. Mayer (Eds), Emotional intelligence in every day life: A scientific inquiry (pp. 113-132). Philadelphia, PA: Psychology Press.

Goldberg, D. P. (1972). The detection of psychiatric illness by questionnaire. London: Oxford University Press.

Goldberg, D. P., \& Hillier, V. F. (1979). A scaled version of the General Health Questionnaire. Psychological Medicine, 9(1), 139-145

Goldberg, D. P., \& Williams, P. (1998). A user's guide to the General Health Questionnaire. Windsor: NFER-Nelson.

Goleman, D. (1995). Emotional intelligence: Why it can matter more than IQ. New York: Bantam.

Goleman, D. (1998b). Working with emotional intelligence. New York: Bantam.

Graczyk, P. A., Matjasko, J. L., Weissberg, R. P., Greenberg, M. T., Elias, M. J., \& Zins, J. E. (2000). The role of the collaborative to advance social and emotional learning (CASEL) in supporting the implementation of quality school-based prevention programs. Journal of Educational and Psychological Consultation, 11(1), 3-6

Hjemdal, O., Aune, T., Reinfjell, T., Stiles, T. C., \& Friborg, O. (2007). Resilience as a predictor of depressive symptoms: A correlational study with young adolescents. Clinical Child Psychology and Psychiatry, 12(1), 91-104

Hoagwood, K., Jensen, P. S., Petti, T., \& Burns, B. J. (1996). Outcomes of mental healthcare for children and adolescents: A comprehensive conceptual model. Journal of the American Academy of Child \& Adolescent Psychiatry, 35 (8), $1055-1063$

Ioannis, T., \& Ioannis, N. (2005). Exploring the relationship of emotional intelligence with physical and psychological functioning. Stress and Health, 21, 77-86

Lam, L., \& Kirby, S. (2002). Is emotional intelligence an advantage? An exploration of the impact of emotional and general intelligence on individual performance. The Journal of Social Psychology, 142(1), 133-143

Lane, R., \& McRae, K. (2004). Neural substrates of conscious emotional experience: a cognitive neuroscientific perspective. Consciousness, emotional self-regulation and the brain, 87-122

Lewinsohn, P. M., Hops, H., Roberts, R. E., Seeley, J. R., \& Andrews, J. A. (1993). Adolescent psychopathology: I. prevalence and incidence of depression and other DSM-III-R disorders in high school students. Journal of Abnormal Psychology, 102(1), 133-144

Martinez-Pons, M. ( 1997). The relation of emotional intelligence with selected areas of personal functioning. Imagination, Cognition and Personality, 17, 3-13

Mayer, J. D., \& Salovey, P. (1997). What is emotional intelligence? In Salovey, P. and Sluyter, D. J. (Eds.), Emotional Development and Emotional Intelligence (pp. 3-31). New York: Basic Books.

Nikolaou, I., \& Tsaousis, I. (2002). Emotional intelligence in the workplace: Exploring its effects on occupational stress and organizational commitment. International Journal of Organizational Analysis, 10(4), 327-342

Palmer, B., Donalson, C., \& Tough, C. (2002). Emotional intelligence and life satisfaction Personality and Individual Differences 33, 1091-1100

Parker, J. D. A., Summerfeldt, L. J., Hogan, M. J., \& Majeski, S. A. (2004). Emotional intelligence and academic success: Examining the transition from high school to university. Personality and Individual Differences, 36, $163-172$ 
Resnick, M. D. (2000). Protective factors, resiliency, and healthy youth development. Adolescent Medicine: State of the Art Reviews, 11(1), 157-164

Salovey, P. (2001). Applied emotional intelligence: Regulating emotions to become healthy, wealthy, and wise. In J. Ciarrochi, \& J.P. Forgas (Eds), Emotional intelligence in everyday life: A scientific enquiry (pp. 168-184). PhiladelphiaPA: Taylor \& Francis.

Salovey, P., \& Mayer, J. D. (1990). Emotional intelligence. Imagination, Cognition and Personality, 9, 185-211

Slaski, M., \& Cartwright, S. (2002). Health, performance and emotional intelligence: an exploratory study of retail managers. Stress and Health, 18(2), 63-68

Taylor, G. J. (2001). Low emotional intelligence and mental illness. In J. Ciarrochi, \& J.P. Forgas (Eds), Emotional intelligence in everyday life: A scientific enquiry (pp. 67-81). Philadelphia, PA: Taylor \& Francis.

Thorndike, E. L. (1920). Intelligence and its uses. Harper's Magazine, 140, 227-235

Trzesniewski, K. H., Donnellan, M. B., Moffitt, T. E., Robins, R. W., Poulton, R., \& Caspi, A. (2006). Low self-esteem during adolescence predicts poor health, criminal behavior, and limited economic prospects during adulthood. Developmental Psychology, 42(2), 381-390

US Department of Health and Human Services (1999). Mental health: A report of the surgeon general. Rockville, MD: US Department of Health and Human Services, Substance Abuse and Mental Health Services Administration, Center for Mental Health Services National Institutes of Health, National Institute of Mental Health.

Vakola, M., Tsaousis, I., \& Nikolaou, I. (2004). The effects of emotional intelligence and personality variables on attitudes toward organizational change. Journal of Managerial Psychology, 19, 88-110

Van der Zee, K., Thijs, M., \& Schakel, L. (2002). The relationship of emotional intelligence with academic intelligence and the Big Five. European Journal of Personality, 16, 103-125

World Health Organization (2004). Promoting mental health: Concepts, emerging, practice Geneva: Department of Mental Health and Substance Abuse, from, [Online] Available: http://www.aihi.unimelb.edu.au/pdf/publications/promotingMentalHealth.pdf

World Health Organization (2007). Strengthening mental health promotion. (Fact Sheet No. 220), [Online] Available: http://www.who.int/mediacentre/factsheets/fs220/en/

Table 1. Mean and standard deviations of main variable.

\begin{tabular}{|l|c|c|c|c|c|}
\hline Variables & $\mathrm{N}$ & Minimum & Maximum & Mean & $\begin{array}{c}\text { Std. } \\
\text { Deviation }\end{array}$ \\
\hline $\begin{array}{l}\text { Emotional Intelligence } \\
(\text { EI })\end{array}$ & 247 & 2.15 & 3.67 & 2.9028 & .29031 \\
\hline $\begin{array}{l}\text { Total Mental Health } \\
(\mathrm{MH})\end{array}$ & 247 & .04 & 2.04 & .9110 & .42770 \\
\hline
\end{tabular}


Table 2. Result of Simple Regression Analysis.

\begin{tabular}{|c|c|c|c|c|c|c|}
\hline Variables & $\begin{array}{c}\text { Summary } \\
\text { of } \\
\text { Regression }\end{array}$ & $\begin{array}{c}\text { Un-std } \\
\text { Coefficient } \\
\text { B }\end{array}$ & $\begin{array}{c}\text { Un-std } \\
\text { Coefficient } \\
\text { Std. Error }\end{array}$ & $\begin{array}{c}\text { Std. } \\
\text { Coefficient } \\
\text { Beta }\end{array}$ & $\mathrm{t}$ & $\begin{array}{l}\text { Sig. } \\
\text { Value }\end{array}$ \\
\hline (constant) & & 3.467 & .220 & & & \\
\hline $\begin{array}{l}\text { Emotional } \\
\text { Intelligence } \\
\text { (EI) }\end{array}$ & & -.880 & .075. & -.598 & -11.67 & .000 \\
\hline Multiple R & $.598 \mathrm{a}$ & & & & & \\
\hline R Square & .357 & & & & & \\
\hline $\begin{array}{l}\text { Adjusted } \\
\text { R Square }\end{array}$ & .354 & & & & & \\
\hline F-Statistics & 136.099 & & & & & \\
\hline
\end{tabular}

Note. Predictor: (Constant), EI. Dependent Variable: Total Mental Health.

$* \mathrm{p}<.05$.

Table 3. Result of Moderated Regression Analysis for the Moderating Effect of Age on link between EI \& Mental Health.

\begin{tabular}{|c|c|c|c|c|c|c|c|c|c|}
\hline \multirow[b]{2}{*}{ Model } & \multirow[b]{2}{*}{$\mathrm{R}$} & \multirow{2}{*}{$\begin{array}{c}\mathrm{R} \\
\text { Square }\end{array}$} & \multirow{2}{*}{$\begin{array}{c}\text { Adjusted } \\
\text { R } \\
\text { Square }\end{array}$} & \multirow{2}{*}{$\begin{array}{c}\text { Std. Error } \\
\text { of the } \\
\text { estimate }\end{array}$} & \multicolumn{5}{|c|}{ Change Statistics } \\
\hline & & & & & $\begin{array}{c}\text { R Square } \\
\text { Change }\end{array}$ & $\begin{array}{c}\mathrm{F} \\
\text { Change }\end{array}$ & df1 & df2 & $\begin{array}{l}\text { Sig. F } \\
\text { Change }\end{array}$ \\
\hline 1 & $.598^{\mathrm{a}}$ & .357 & .354 & .34363 & .357 & 136.09 & 1 & 245 & .000 \\
\hline 2 & $.598^{b}$ & .357 & .352 & .34433 & .000 & .003 & 1 & 244 & .955 \\
\hline
\end{tabular}

Note. Predictors step 1: Total EQ, Predictors step 2: Total EQ, Students Age

$* \mathrm{p}<.05$. 